\title{
Trabalho subordinado
e qualidade de vida:
conciliação impossível
}

Subordinate work and quality of life: conciliation impossible Giuseppina De Grazia, ${ }^{*}$ Gabriela Cavalcante
da Silva, ${ }^{* *}$ Ingrid Adame Moreira***

Resumo: $O$ artigo trata da deterioração da condição humana resultante das novas formas de subjugação do trabalho ao capital, a partir de alguns resultados preliminares de pesquisa desenvolvida junto a algumas categorias de trabalhadores na Região Metropolitana do Rio de Janeiro. Busca-se aprofundar a investigação em relação às consequências do alastramento de fenômenos que se reproduzem em escala mundial como desemprego, trabalhos parciais e precarizados, concomitantemente a uma brutal intensificação do trabalho em jornadas que se prolongam noite adentro e fins de semana, invadindo e subjugando os demais tempos sociais. As consequências destrutivas, tanto no que se refere à vida pessoal, à saúde física e mental, como ao conjunto das relações sociais, ao contrário do que afirmam algumas teorias recentes, reforçam a vigência da centralidade do trabalho na vida humana. Simultaneamente, porém, atestam a contradição insolúvel entre o trabalho subordinado aos interesses do capital e a emancipação humana.

Palavras-chave: tempo de trabalho; precarização; intensificação do trabalho.

\begin{abstract}
The article deals with the deterioration of the human condition resulting from new forms of subjection of labor to capital, from preliminary results of a research project carried out for some categories of workers in the metropolitan area of Rio de Janeiro. We seek to further research about the consequences of the spread of phenomena that breed worldwide as unemployment, part time and precarious work concurrently to a brutal intensification of work hours that extend
\end{abstract}

\footnotetext{
* Doutora em Sociologia pela Universidade de São Paulo (USP), professora no Depto. de Serviço Social de Niterói da Universidade Federal Fluminense (UFF - Campus do Gragoatá - Niterói/RJ). Correspondência: Rua Dois de dezembro n. 22, apto 707, Flamengo - CEP 22220040, Rio de Janeiro/RJ. E-mail: <pina.gr@uol.com.br>.

** Graduanda em Serviço Social da Universidade Federal Fluminense (UFF - Campus do Gragoatá / Niterói/RJ). Correspondência: Rua Professor Hernani Pires de Mello, n. 02, São Domingos - CEP: 24210-130 - Niterói/RJ. E-mail: <gabiblessed@yahoo.com.br>.

*** Mestranda em Serviço Social e Desenvolvimento Regional na Universidade Federal Fluminense (UFF - Campus do Gragoatá / Niterói/RJ). Correspondência: Rua Ouro Branco, lote: 22, quadra: 46 - Jardim Catarina - CEP 24715642 - São Gonçalo/RJ. E-mail: <ingridadameuff @gmail.com>.
} 


\begin{abstract}
into the night and weekends, invading and subjugating other social times. The destructive consequences, both in terms of personal life, to physical and mental health, as the ensemble of social relations, unlike some recent theories, reinforce the validity of the centrality of work in human life. Simultaneously, however, attest to the insoluble contradiction between the work subordinate to the interests of capital and human emancipation.
\end{abstract}

Keywords: work time; precarization; work intensification.

\title{
Introdução
}

Este artigo tem como base os estudos que vêm sendo realizados no Projeto de Pesquisa "Tempo de trabalho e tempo para a vida: uma unidade conflitante", desenvolvido no Curso de Serviço Social da Universidade Federal Fluminense, assim como a coleta de dados empíricos - pesquisa qualitativa - junto a trabalhadores inseridos na indústria, comércio e prestação de serviços. O projeto tem como objetivo traçar um paralelo entre as peculiaridades e as características comuns de categorias diferenciadas de trabalhadores, a fim de investigar como concretamente incidem e são percebidos os impactos da reestruturação produtiva em diferentes setores da economia.

Com estudos largamente conhecidos, tais como os de Antunes (1999) e Alves (2000), entre muitos outros, inúmeras análises já demonstraram como a reestruturação produtiva, simultaneamente à disseminação das políticas e ideologia neoliberal, vem impactando o mundo do trabalho nas últimas décadas, com danos irreparáveis no que diz respeito à perda de direitos sociais, fragmentação e alteração das condições objetivas e subjetivas da classe trabalhadora.

Dentro desse quadro, o presente trabalho tem como enfoque específico a preocupação de investigar as características da jornada e condições de trabalho na sociedade contemporânea, em articulação com seus rebatimentos nos demais tempos sociais da vida fora do trabalho remunerado, assim como verificar os danos infligidos à saúde física e mental desses trabalhadores.

A partir da perspectiva da teoria social crítica, na fase inicial do projeto procedeu-se ao levantamento e estudo sistemático da bibliografia para aprofundar o conhecimento a partir das análises já realizadas nesse campo temático. De importância fundamental para o embasamento teórico dos integrantes do grupo, a pesquisa e o debate da bibliografia continuam acompanhando todas as etapas do projeto de pesquisa. 
No primeiro semestre de 2011, paralelamente à continuidade dos estudos, teve início a pesquisa de campo, entrevistando, numa primeira fase, representantes de sindicatos de diversas categorias, centrais sindicais e Departamento Intersindical de Estatística e Estudos Socioeconômicos (DIEESE), para obter um panorama geral do trabalho na Região Metropolitana do Rio de Janeiro.

Com os dados coletados, optou-se por iniciar a pesquisa qualitativa com os trabalhadores do comércio, do telemarketing (setor de serviços) e as costureiras (indústria de confecção) a partir dos seguintes critérios: quantidade de trabalhadores expressiva; diversificação representativa das práticas flexíveis de gestão do trabalho vigentes na atualidade: diversidade de vínculos, locais de trabalho desconcentrados, incluindo o domicílio, jornadas irregulares, grande proporção de trabalho feminino e grande incidência de problemas relativos à inter-relação trabalho $x$ vida' ${ }^{1}$.

As 65 entrevistas realizadas até o momento foram feitas a partir da utilização de questionário semiestruturado com perguntas fechadas e abertas, buscando apreender tanto os dados objetivos (tipo de vínculo, duração da jornada etc.) como, principalmente, a percepção de cada trabalhador a respeito de sua realidade. ${ }^{2}$

Antes de apresentar alguns dos resultados preliminares obtidos na pesquisa de campo, segue uma tentativa de contextualização do quadro mais geral que caracteriza o mundo do trabalho na atualidade, com ênfase no debate a respeito das questões específicas abordadas na pesquisa.

\section{A subjugação da vida ao tempo de trabalho remunerado}

As explosões de revolta de milhares de indignados, principalmente jovens sem perspectivas de futuro, e as inúmeras manifestações cada vez mais frequentes no cenário mundial, agora atingindo intensamente inclusive os países centrais, acabam constantemente trazendo de volta debates relacionados à questão do desemprego - sempre o efeito mais imediato das crises econômicas e das invariáveis políticas recessivas adotadas pelos governos neoliberais. Embora permanente e imprescindível ao modo de produção capitalista, o aumento explosivo do número de pessoas fora do mercado de trabalho frequentemente também traz temores associados a situações fora de controle, inclusive para os extratos mais privilegiados da sociedade.

No extremo oposto, com menos visibilidade, os danos infligidos ao desenvolvimento físico e mental dos milhões de seres humanos que, em

\footnotetext{
1 O projeto ainda está em andamento, e estão previstas ainda entrevistas com outras categorias da indústria e serviços como metalúrgicos, bancários, professores, além de assistentes sociais. 2 As entrevistas foram realizadas após expresso consentimento dos participantes, de acordo com os procedimentos definidos na Declaração de Helsinque V, 1996, e na Resolução 196/96 do Conselho Nacional de Saúde.
} 
troca de remuneração para a sobrevivência, consomem a maior parte do tempo da vida em função do trabalho, nem sempre são percebidos propriamente como questão social. Ao contrário, aqueles que ainda conseguem encontrar compradores para sua força de trabalho em empregos regulares e tempo integral, em geral são vistos como bem-sucedidos tanto pela mídia, quanto pelos próprios familiares e a sociedade em geral. Menos ainda é percebida a profunda inter-relação entre os dois fenômenos.

Para a sociedade fundada sobre a moral do trabalho, o sofrimento provocado pelo trabalho estranhado, assim como a intensificação e o alongamento das jornadas (verificado em diversos países a partir das últimas décadas do século XX), além de não serem motivos de grandes preocupações, não são percebidos como a contrapartida obrigatória ao aumento proporcional do desemprego.

A clara evidência de que o tempo de trabalho necessário à produção de bens e serviços diminuiu significativamente devido ao extraordinário aumento da produtividade ao longo do último século, não tem sido suficiente para impedir a continuidade de uma realidade paradoxal em que grandes contingentes veem prejudicadas sua saúde, sua vida social, intelectual, a convivência familiar, etc., devido à obrigatoriedade de longas e intensas jornadas de trabalho, ao mesmo tempo em que outros milhões enfrentam a desocupação compulsória e a negação do direito ao trabalho.

Além de maior número de horas ocupadas no trabalho, como decorrência da reestruturação produtiva - implementada a partir dos anos 1970 com a finalidade de recuperar a lucratividade do capital em crise verifica-se uma alteração no próprio conceito de tempo de trabalho, tornando insuficiente analisar a jornada destinada à atividade remunerada apenas do ponto de vista de sua duração.

A guerra de competitividade acirrada pela mundialização do capital e a consequente necessidade ilimitada de eliminar custos, impôs a necessidade de superar a rigidez do modelo fordista, buscando maior agilidade no atendimento às oscilações de um mercado cada vez mais exigente e globalizado. Para isso, torna-se imprescindível contar com uma força de trabalho com disponibilidade absoluta, livre de regulamentações, horários rígidos, ou quaisquer outras formalidades que possam impedir sua utilização em grau máximo e nas formas mais diversificadas. Assim, tanto o local quanto o horário de trabalho - em grande parte graças às facilidades oferecidas pela informática e demais tecnologias de comunicação - não necessariamente precisam ficar limitados ao interior da empresa, podendo se estender ao domicílio, ao trajeto casa - trabalho ou aos locais de lazer. Da mesma forma, os vínculos empregatícios formais e rígidos que estabeleciam as normas contratuais entre empregado e empregador podem ser substituídos por formas menos onerosas de contratação, com a vantagem de sua utilização temporária e pontual, estritamente ajustada às oscilações da demanda. 
A ampliação das novas modalidades de subjugação do trabalho ao capital, além de tornar a atividade laborativa mais penosa, tem trazido profundas mudanças no que diz respeito ao entrelaçamento entre vida $e$ trabalho, desfazendo as demarcações, até certo ponto bem delimitadas entre o tempo despendido dentro do trabalho remunerado e fora dele. A disciplina dos horários rígidos imposta duramente pela revolução industrial é substituída pelas exigências atuais do capital, as quais, também de forma unilateral, instauram a diluição daquelas demarcações, abrindo as comportas que possibilitam ao trabalho invadir e subordinar, sem qualquer entrave, a esfera da vida privada.

A vinculação permanentemente propagandeada entre o sucesso da empresa e a continuidade do emprego, as diversas formas de buscar o envolvimento do trabalhador, seja através da pressão direta para o cumprimento de metas em prazos cada vez mais curtos, seja através de métodos mais sutis e inteligentes que os utilizados pelo taylorismo, além de sugarem intensamente todas as energias disponíveis, têm levado as preocupações e o stress do trabalho a interpenetrarem o tempo da vida, interferindo nas relações afetivas, prejudicando o sono, o lazer e demais atividades.

A situação da mulher trabalhadora, cuja presença no mercado de trabalho tem assumido proporções cada vez mais amplas, pode ser apontada como a expressão mais aguda dos dilemas concernentes à conexão vida e trabalho. Todos os velhos e conhecidos problemas da dupla jornada são potencializados ao extremo na sociedade contemporânea, tanto quantitativa quanto qualitativamente.

As estatísticas de aumento do stress, dos problemas de depressão e esgotamento mental, além da intensificação dos casos de Lesões por Esforços Repetitivos (LER) e outras doenças profissionais, comprovadas por inúmeros estudos e estatísticas oficiais, como decorrência do trabalho na atualidade, assim como as inúmeras consequências do desemprego massivo, são indicativas da aparente irracionalidade - extremamente funcional - do sistema de organização social dirigido prioritariamente a garantir a acumulação do capital em detrimento das necessidades humanas.

Entre os enormes contingentes fora do mercado formal, o tempo de trabalho é ainda mais irregular, com jornadas muitas vezes mais longas que também interpenetram o tempo de vida com os mesmos prejuízos já apontados. Realidade sentida, inclusive, pelos que acreditam trabalhar "por conta própria", embora submetidos a um assalariamento camuflado, recebendo por produção, seja no próprio domicílio, como "pessoa jurídica" ou prestador "autônomo". Mesmo em situação de desemprego, ou quando a quantidade de horas efetivamente ocupadas com pequenos "bicos" é inferior à jornada legal, a própria irregularidade e insegurança quanto à garantia de encontrar novo trabalho ou novos clientes, invadem da mesma forma o tempo de não trabalho, afetando o convívio familiar e as demais dimensões da vida. 
Enfim, a totalidade da existência, a sociabilidade e inquietações humanas, tanto dos que ainda contam com vínculo empregatício, quanto dos desempregados e precarizados, a despeito das teorias questionadoras da centralidade do trabalho, continuam mais do que nunca atadas ao trabalho - ou à falta dele -, uma vez que este, na sociedade comandada pelo capital, constitui-se no único meio através do qual se torna possível a reprodução da vida.

As diversas teorias que, principalmente no fim dos anos 1980 apontavam para um possível fim da sociedade fundada no trabalho, advento da "sociedade do tempo livre" e coisas do gênero (OFFE, 1989; GORZ, 1982; RIFKIN, 1995, entre outros), parecem ter entrado em declínio mais recentemente. A própria desestruturação da vida social e pessoal, decorrente do aumento de parcelas cada vez maiores em situações de desemprego aberto ou disfarçado, sinaliza a permanência da centralidade do trabalho enquanto elemento estruturante das relações humanas, mesmo com todas as contradições inerentes ao trabalho abstrato dentro da sociedade capitalista. Ao mesmo tempo, a insatisfação generalizada e os sofrimentos decorrentes do trabalho estranhado - inconciliável com a emancipação e o desenvolvimento integral do gênero humano - reafirmam permanentemente a necessidade de se recuperar a dimensão ontológica do trabalho, enquanto categoria central e indissociável do ser social.

A debilidade das teorias do fim do trabalho também é questionada pela própria realidade empírica. Diversos estudos mostram que, mesmo com todo avanço tecnológico, a quantidade total de horas de trabalho aumentou quase um quarto no conjunto dos seis países mais desenvolvidos entre 1960 e $1996^{3}$.

Mais recentemente, Francisco de Oliveira (2009) lembra que nas últimas duas décadas, cerca de 800 milhões de pessoas - quase quatro vezes a população total do Brasil - ingressaram no mercado de trabalho na China, Índia e demais países asiáticos. A fantástica quantidade de valor produzida por essa força de trabalho, sem o correspondente aumento do poder aquisitivo dos trabalhadores em qualquer país do planeta - impedindo consequentemente a realização desse valor - é apontada por ele como a verdadeira origem da atual crise - definida em geral como apenas uma crise financeira ${ }^{4}$.

Mais que a demanda por trabalho humano, o que realmente sofreu uma diminuição acelerada foi o trabalho formal e estável, dando lugar a inúmeras formas de trabalho parcial e precarizado. A necessidade do capital de sempre buscar as formas mais eficazes de exploração e aumento de pro-

\footnotetext{
${ }_{3}^{3}$ Dados da OCDE analisados por Michel Husson (2001), referentes aos EUA, Japão, Alemanha (sem RDA), Reino Unido, França e Itália.

4 Disponível em: <http://www.cartamaior.com.br/templates/materiaMostrar.cfm?materia_id= 15900>. Acesso em: 02 abr. 2009.
} 
dutividade, implica, nos dias atuais, na utilização de modelos produtivos flexíveis e com os menores custos salariais possíveis - mecanismos totalmente coerentes com a essência do capital, e utilizados em diferentes formatos ao longo de toda sua história. Trata-se apenas, no momento, de uma melhor adequação das formas de exploração do sobretrabalho.

Embora a tendência no modo de produção capitalista seja empregar sempre a maior parte do excedente na compra de meios de produção, em detrimento da absorção da força de trabalho, o trabalho vivo não pode ser eliminado do processo de produção de mercadorias. O capital "pode incrementar ao máximo o trabalho morto corporificado no maquinário tecnocientífico, aumentando deste modo a produtividade do trabalho de modo a intensificar as formas de extração do sobretrabalho em tempo cada vez mais reduzido". (ANTUNES, 2005, p.14). Porém jamais poderia extinguir totalmente o trabalho assalariado, pois estaria eliminando sua fonte de extração de mais-valia. Mesmo que quantitativamente o trabalho vivo se torne irrelevante, ele será sempre imprescindível. "A articulação entre o trabalho vivo e o trabalho morto é condição para que o sistema produtivo do capital se mantenha." (ANTUNES, 1999, p.120).

O fim do trabalho assalariado só poderia ocorrer com o fim do sistema comandado pelo capital. E, mesmo neste caso, não significaria a eliminação do trabalho humano enquanto atividade útil e necessária à vida em sociedade, enquanto "atividade orientada a um fim para produzir valores de uso, apropriação do natural para satisfazer as necessidades humanas, condição universal do metabolismo entre o homem e a natureza, condição natural eterna da vida humana [...]". (MARX, 1988, p. 146).

\section{O trabalho intensificado}

Inúmeras pesquisas a respeito das transformações recentes no mundo do trabalho apontam um processo de intensificação do trabalho sem precedentes, aliado a um alto grau de pressão e controle, graças aos novos métodos de gestão da produção e às possibilidades abertas pelos recursos tecnológicos contemporâneos. Por isso, em qualquer estudo a respeito da mensuração do tempo ou da quantidade de trabalho, é impossível desvincular a questão da duração, da análise de sua intensidade, do grau de controle, alienação e exploração do trabalho. "Qualidade e quantidade do trabalho constituem uma unidade dialética". (MAGNIADAS, 1996, p.1).

Para Renato Di Ruzza (2000), a duração do trabalho é apenas a forma mais simples de quantificar o trabalho. As outras duas dimensões são a sua intensidade e sua complexidade. A intensidade é mais difícil de ser mensurada porque é preciso levar em conta, além do ritmo (o número de movimentos efetuados por unidade de tempo), o conjunto dos elementos que determinam todo o desgaste de energia e fadiga física e mental. Implica 
na necessidade de considerar o conteúdo do trabalho, como é gerido e organizado, os efeitos sobre a saúde, assim como as avaliações subjetivas determinadas pelas diversas formas de sentir o "peso" do trabalho. Em relação ao terceiro elemento, a complexidade do trabalho, aceita-se em geral o entendimento de sua vinculação com a hierarquia salarial, isto é, quanto maior complexidade, maior o salário.

Embora sempre presentes, a "arquitetura" dessas três dimensões varia em cada época histórica, diz o autor citado. Ela permaneceu estável nos três quartos de século em que predominou o modelo taylorista, quando a dimensão temporal era preponderante, a complexidade tinha que ser eliminada o mais possível (com a simplificação máxima das tarefas) e a intensidade parecia simplesmente determinada pela técnica, subordinada à máquina, portanto fora de qualquer discussão ou negociação. (DE GRAZIA, 2007). ${ }^{5}$

Para maximizar os ganhos de produtividade, o método de Taylor, associado à racionalização fordista, se especializou em desenvolver um sofisticado sistema de controle de cada movimento do trabalhador com a finalidade de aumentar sua agilidade e evitar o desperdício de qualquer um dos minutos contidos dentro do horário de trabalho. A incessante busca de conversão dos tempos mortos em tempo produtivo caracterizou o modelo configurado pela produção em série, a divisão de trabalho levada ao seu mais alto grau, organização hierárquica rígida, etc. O cronômetro era o principal instrumento de gestão, pois cada vez que o trabalhador usasse o tempo de trabalho para si mesmo, estaria roubando um tempo comprado pelo capital.

Também para os trabalhadores e suas organizações sindicais, a duração desse tempo delimitado de sua jornada vendido ao capital e as condições monetárias referentes à sua remuneração, eram o centro das preocupações e das reivindicações nesse período, lembra Di Ruzza (2000).

Com o esgotamento do taylorismo-fordismo - entre outros motivos, inclusive pelo fracasso de jamais ter alcançado o objetivo de controlar completamente o tempo de cada trabalhador, as interferências indevidas de sua subjetividade, a rebeldia individual ou coletiva - o capital descobre formas mais eficazes de usufruir da força de trabalho, ultrapassando os limites temporais colocados pela jornada de trabalho e, mais importante, enredando a própria subjetividade do trabalhador, além de seu tempo e seus movimentos físicos. Os representantes do capital percebem que, guiados apenas pelo relógio, sempre havia a possibilidade de serem "roubados". Por isso passaram a utilizar medidas e instrumentos mais sutis e inteligentes para garantir a subjugação da força de trabalho.

\footnotetext{
5 Neste e nos parágrafos seguintes são reproduzidas as principais considerações feitas em De Grazia (2007, p. 51-55).
} 
Nos novos padrões produtivos, outras formas de controle e mensuração da eficácia do trabalho substituem o relógio e o cronômetro. $\mathrm{O}$ que interessa são os resultados, e o empenho das diversas equipes de trabaIhadores na obtenção das metas e prazos estabelecidos pela empresa. Exigese um maior grau de responsabilidade, ampliação e diversificação de atribuições, e, principalmente, envolvimento pessoal na obtenção dos resultados.

O antigo sonho taylorista nunca atingido - coincidência de objetivos entre capital e trabalho - é agora, pelo menos em parte alcançado, inclusive com a dispensa de grande parte do enorme exército de chefes e supervisores, substituídos com mais eficácia pela autodisciplina e o controle mútuo entre os próprios trabalhadores. O trabalhador não pode mais se dar ao luxo de "fazer cera", "morcegar", ou buscar qualquer outro artifício para escapar à opressão contínua. Ao contrário, tem que se empenhar, física e mentalmente, para o cumprimento das metas nos seus devidos prazos. Se necessário, ele mesmo, por iniciativa própria, fica além do horário normal, ou leva trabalho para casa - e mesmo que isto não aconteça, em casa continua preso à preocupação de cumprir as metas, cujo medo do fracasso Ihe tira o sono, prejudica seus relacionamentos, etc. Caem os limites, portanto, que separam e anunciam quando termina o tempo que o trabalhador vende ao empregador, e quando começa o tempo que lhe pertence.

Em suma, o processo de intensificação do trabalho, sempre presente em toda a história da produção capitalista, adquire hoje novas formas, associado à complexificação das tarefas, à polivalência crescente, e, principalmente, à medida que a força de trabalho é impelida a assumir para si o que era tarefa apenas dos representantes do capital: buscar todas as formas de eliminar os tempos mortos, eliminar custos, melhorar a qualidade, etc.

O resultado dessa nova forma de servir ao capital transparece nas inúmeras estatísticas e estudos de médicos e ergonomistas que demonstram altíssimos aumentos de stress e de uma quantidade enorme de doenças profissionais, além dos prejuízos à vida pessoal, familiar e social. Situação que atinge tanto trabalhadores sem qualificação profissional, quanto executivos, técnicos e trabalhadores qualificados em geral.

Por isso, voltando ao raciocínio de Di Ruzza (2000), a dimensão da duração do trabalho adquire um peso menor atualmente, enquanto a complexidade e intensidade ganham importância preponderante na arquitetura dos novos modelos produtivos pós-fordistas.

As novas tecnologias ligadas às redes de informática e telecomunicações também são utilizadas como instrumentos de controle e pressão sobre o volume, a qualidade e a rapidez do trabalho por abrirem a possibilidade de manter os trabalhadores conectados às necessidades da empresa mesmo fora dos horários de trabalho, ou diretamente aos que Ihes cobram sempre maior qualidade em tempo cada vez mais curto. 
As frustrações são mais vivas e o stress mais forte, na medida em que os clientes exijam uma resposta, uma entrega ou um serviço num prazo mais curto. A tal ponto que a direção das empresas recorre cada vez mais raramente a ordens autoritárias. A pressão da clientela basta [...]. Sofrem um duplo stress: um, ligado ao cliente (nem sempre amável), e outro ligado à complexidade da máquina [...]. Além disso, ficam de olho fixo no contador de espera, que mostra o número de pessoas na linha. 'Para o empregado, há um lado esquizofrênico: por um lado, a direção the pede qualidade (satisfação, fidelidade do cliente, etc.), e por outro, rapidez. O que muitas vezes é inconciliável.'. (BULARD, 2000, s.p.) ${ }^{6}$.

Em tempos de crescentes exigências de flexibilização tanto no setor produtivo quanto na prestação de serviços, a duração e intensidade do trabalho ficam subordinados ao "mercado e à sua elasticidade. [O que pressupõe uma igual] flexibilização da disponibilidade em alienar o tempo de trabalho, [e um] completo devotamento ao tempo de trabalho" (PEPE, 1998, p.84-85), a ponto de, no limite, ficar 24 horas por dia, doze meses por ano, conectado e à disposição das necessidades da empresa, clientes e consumidores - ou à procura ansiosa por eles. Trata-se da generalização da "absoluta interiorização da identidade entre tempo de trabalho e de não trabalho" (PEPE, 1998, p.84-85), onde o tempo de vida é absorvido pelo tempo de trabalho, sendo o tempo de não trabalho considerado um "desperdício econômico". (PEPE, 1998).

Uma realidade que pode ser aplicada tanto aos trabalhadores precarizados, terceirizados, autônomos, a domicílio, quanto àqueles que trabalham sob o regime de jornadas flexíveis ou banco de horas em que a variação da duração da jornada está sempre subordinada às necessidades e ritmos da empresa, e, portanto dificilmente coincidente com calendário escolar, férias da família, horários de cursos, etc. Para o trabalhador, portanto, além do frequente aumento no volume e ritmo de trabalho mesmo quando sua duração é mais curta - além da perpetuação da alienação e total ausência de autocontrole sobre seu trabalho, também o seu tempo de não trabalho fica submetido ao controle do empregador, não podendo programar a vida a partir de suas necessidades pessoais ou familiares.

Por todos os lados que se olhe, aliás, o tempo fora do trabalho subordinado está condicionado tanto pela quantidade quanto pela qualidade do trabalho e sua remuneração. Esse conjunto de fatores vai influenciar diretamente a qualidade de vida fora do trabalho, as formas de lazer, o acesso aos bens e serviços, à cultura, a plena realização como ser social. Constituindo uma unidade dialética, o tempo do trabalho remunerado e o tempo da vida não podem ser considerados separadamente se a emancipação hu-

${ }^{6}$ Versão on-line. Disponível em: <http://www.diplomatique.org.br/acervo.php?id=253>. Acesso em: 10 dez. 2003. 
mana estiver colocada como o norte de referência para uma transformação social.

Tanto as novas formas de flexibilização e intensificação do trabalho, como as múltiplas inter-relações entre vida e trabalho adicionam maior complexidade às lutas atuais da classe trabalhadora, inclusive em relação à bandeira de redução da jornada de trabalho, dificultando a enorme tarefa de recolocá-las na direção do que Alain Bihir (1998) define como a essência da questão: a retomada, por parte dos produtores diretos, do controle sobre o processo de trabalho, expropriado pelo capital.

\section{A percepção dos sujeitos da pesquisa}

A pesquisa parcial realizada na Região Metropolitana do Rio de Janeiro - a maior parte nos municípios de Niterói e São Gonçalo - forneceu os primeiros dados empíricos que permitem, a título de observações preliminares, comprovar a veracidade dos estudos teóricos expostos até aqui. Os relatos dos diversos trabalhadores entrevistados confirmam a existência de uma significativa intensificação do trabalho, juntamente à tendência de tornar o trabalhador polivalente (sem acréscimo salarial).

Em relação ao ritmo de trabalho, mais da metade dos entrevistados consideraram-no acelerado ou muito acelerado. Entre os operadores de telemarketing o quantitativo chegou a $75 \%$ dos entrevistados.

[A gente] faz tudo ao mesmo tempo. Como é fast-food, tem que ter agilidade, rapidez. Muita pressão da gerência para preparar o pedido rápido, cobra muitas coisas desnecessárias. Não entende que somos uma pessoa só. (Atendente, 19 anos, grande rede de lanchonetes, Niterói).

Eu tenho que dar conta de tudo, ser prática e ágil. A empresa exige isso do funcionário até mesmo pra crescer na empresa. (Atendente, 23 anos, grande rede varejista de vestuário e derivados).

Em grande parte como consequência desse ritmo e das condições de trabalho, verifica-se grande número de problemas na saúde dos trabaIhadores e de várias doenças físicas e mentais. Algumas doenças mais recorrentes puderam ser relatadas pelos entrevistados, tais como: estresse, problemas gástricos, psicológicos (síndrome do pânico, depressão), problemas de coluna (no caso das costureiras), tendinite e problemas auditivos (no caso dos operadores de telemarketing), problemas de circulação, pressão alta, entre outras doenças.

Problema ginecológico decorrente de estresse, dor de ouvido, infecção urinária, laringite, sinusite [...] Basicamente estresse decorrente do 
trabalho, [infecção por causa] da não possibilidade de ir ao banheiro, etc. (Atendente, 27 anos, grande rede de telemarketing).

Tendinite pelo uso repetitivo das ferramentas de trabalho e o estresse pelo número de reclamações... Era uma fila de 200 a 500 pessoas hoje para ser atendidas. (Atendente, grande rede de telemarketing).

Já tive problemas de circulação sanguínea, pé inchado, úlcera de nível 3. Trabalho em pé o dia todo [...] Já teve vezes que trabalhei doze horas de pé. (Vendedora, 25 anos, loja de roupas).

Tô tomando dois [medicamentos] tarja preta. É muita tortura psicológica . Não pode nem olhar pro lado. Eu tava bocejando, [a dona] falou que eu estava conversando. (Costureira, 41 anos, empresa de confecção).

Em relação ao que consideravam como os principais problemas vivenciados no local de trabalho, o mais apontado, por cerca de $71 \%$ dos entrevistados, principalmente entre os comerciários, foi a obrigatoriedade de trabalhar nos finais de semana. O que pode explicar diversas afirmações verificadas ao longo dos depoimentos como "queria dar mais atenção ao meu filho", ou "queria estar mais tempo com minha família", "só tenho uma folga por semana e não dá para fazer nada", entre várias outras queixas semelhantes.

Os baixos salários foram identificados por $62 \%$ no conjunto das três categorias como sendo o segundo maior problema. Característica inerente e imprescindível ao modo de produção capitalista, esta realidade de baixos salários não poderia deixar de estar presente na realidade pesquisada. O quantitativo dos lucros das empresas empregadoras torna-se tanto mais exorbitante quanto maior a degradação dos trabalhadores. Em seguida, o trabalho estressante, monótono e repetitivo foi citado como o terceiro maior problema, chegando ao índice de 54\% dos entrevistados, com maior incidência entre os operadores de telemarketing.

No setor de confecções, 30\% das entrevistadas declararam trabalhar em pequenas oficinas terceirizadas e 70\% em seu domicílio. Analisando os problemas expostos pelas costureiras que trabalham a domicílio, temos a longa jornada como principal queixa. Esta jornada é autoimposta por não terem horário estabelecido pelo empregador direto. Em compensação, os compradores de suas peças pagam valores irrisórios por cada peça e estabelecem um determinado prazo de entrega que as obrigam a intensificar sua produção e alongar seu tempo de trabalho.

Por causa dos prazos... sou eu pra tudo. [...] Quando chega quinta, sexta não aguento mais. (Costureira, 43 anos, domicílio).

Esse tipo de trabalho, considerado ilusoriamente como "autônomo", camufla a relação de assalariamento por um contrato aparentemente 
comercial, através do pagamento por peça ou por serviço prestado, sendo totalmente conveniente aos interesses dos empregadores. Sem estabelecer um contrato formal de trabalho com as costureiras, não necessitam custear o local de trabalho (gastos como luz, água e toda infraestrutura necessária), além de não pagar os encargos e driblar a obrigatoriedade de conceder os direitos trabalhistas garantidos na Consolidação das Leis do Trabalho (CLT), tais como o $13^{\circ}$ salário, as férias e o auxílio doença.

Entre os comerciários, a pressão para atingir metas e o desentendimento com colegas tiveram maior destaque. Este último problema pode estar vinculado ao ambiente competitivo de trabalho, cada vez mais estimulado pela contínua necessidade de disputar os clientes para poder alcançar as metas. Quanto à carga horária, 80\% dos entrevistados declararam trabalhar mais de 44 horas semanais, o que configura uma jornada de trabalho acima da jornada legal no país.

Você não entra só pra vender. A loja é pequena e se não tem quem faça tal trabalho, você é obrigada a fazer. Existe pressão porque trabalho com metas. Trabalhar com metas é uma pressão muito grande. (Vendedora, 25 anos, loja de roupas).

Entre os operadores de telemarketing também há reclamação em relação à pressão existente para o cumprimento de metas. Ao fim da jornada de trabalho $40 \%$ se declaram extremamente cansados. A jornada de trabalho do telemarketing tem duração de seis horas diárias (incluindo as pausas que possuem por direito, como para ir ao banheiro e alimentação) ${ }^{7}$. No entanto, os níveis de estresse são elevadíssimos devido à intensidade e a complexidade do trabalho.

Pela demanda de ligações, existe pressão por parte dos supervisores para que não se forme uma fila de espera no atendimento. O supervisor também recebe pressão de seu supervisor, que também é pressionado, ou seja, a pressão é hierarquizada. (Atendente, grande rede de telemarketing).

Tem dia que parece uma eternidade, depende do número de ligações. Tem dia que você quer sair dali correndo, que a hora não passa. (Operadora de telemarketing, 22 anos).

O perfil dos trabalhadores do telemarketing é de jovens que estudam antes ou após o expediente de trabalho, o que torna o trabalho diário ainda mais cansativo devido à quantidade de atividades exercidas ao longo

\footnotetext{
${ }_{7}$ Conforme dispõe o item 5.3, Anexo II da Norma Regulamentadora NR-17, de 30/03/2007. Disponível em: <http://portal.mte.gov.br/data/files/FF8080812BE914E6012BEFBDACD94B74/ nr_17_anexo2.pdf>. Acesso em: 20 abr. 2012. (BRASIL, 2007).
} 
do dia. Muitos ainda são responsáveis pelas tarefas domésticas, principalmente entre as mulheres.

É pouco tempo. Não dou conta de fazer as coisas. Fazer a janta do marido, estudar, ler os textos e lavar roupas. Falto aula para fazer alguma coisa pendente em casa. (Atendente, grande rede de telemarketing).

Poderia me dedicar mais aos estudos e ao namorado, pois já perdi 3 namorados por não ter tempo. O trabalho me consome. (Atendente, 27 anos, grande rede de telemarketing).

Por ser um trabalho muito estressante, não consigo ter um bom rendimento na faculdade e até mesmo nas relações familiares. (Atendente de telemarketing).

O capitalismo possui a capacidade de constantemente se reconfigurar, criando novas formas de exploração sem perder a essência que garante a manutenção da sua existência - utilizar a força vital dos trabalhadores (força de trabalho) para gerar seus lucros. Nos primórdios do regime capitalista, quando as inovações técnicas avançavam com lentidão, o aumento da quantidade de mais-valia por operário ocupado só era possível mediante a mais-valia absoluta, isto é, mediante prolongamento da jornada de trabalho, de tal maneira que o tempo de sobretrabalho (criador de mais-valia) aumentasse, enquanto se conservava igual o tempo de trabalho necessário (criador do valor do salário).

No entanto, com o avanço das leis que regulam as relações de trabalho, inclusive o estabelecimento do tempo de trabalho, o capitalista visando não ter queda na taxa de lucros, passou a utilizar a mais-valia relativa. Esta resulta do acúmulo de inovações técnicas e/ou da intensificação do trabalho, elevando a produtividade sem alteração da jornada. A elevação da produtividade social do trabalho contribui para diminuir o valor dos bens de consumo necessários à subsistência da força de trabalho, exigindo por isso menor tempo de trabalho para a sua reprodução. Desta forma, tornou-se possível, dentro de uma mesma quantidade de horas de trabalho, diminuir o tempo de trabalho necessário, em contrapartida ao crescimento do tempo de sobretrabalho. Se no século XIX a forma de exploração que predominava era a extração da mais-valia absoluta ${ }^{8}$ em pleno século XXI observamos a repaginação da exploração, desta vez predominantemente (e não exclusivamente) por meio da extração de mais-valia relativa.

Por isso, mesmo que a jornada de trabalho seja de seis (como no caso dos operadores de telemarketing) ou oito horas semanais, as características do trabalho na contemporaneidade tornam o exercício desta ativi-

\footnotetext{
${ }^{8}$ Marx relata no capítulo VIII de O Capital [v. 1, livro 1, 1996] que, na década de 1860, nas fábricas inglesas, até crianças chegavam a trabalhar 18 horas por dia, às vezes mais.
} 
dade extremamente cansativa física e mentalmente para as diversas categorias profissionais. E isto reduz a possibilidade de tais trabalhadores usufruírem um tempo suficiente para uma vida fora do trabalho que permita a realização plena do ser humano em todas as dimensões: espiritual, cultural e socialmente.

Tendo em vista a realidade dos trabalhadores entrevistados, é possível compreender o porquê de cerca de $70 \%$ afirmarem que o tempo que Ihes sobra fora do trabalho é insuficiente para atender às suas necessidades.

Gostaria de estudar e não dá. Ficar com minha família ser mais presente na vida dela... (Atendente comercial, 23 anos, grande rede varejista multinacional de vestuário e derivados).

Estou insatisfeito, porque é pouco tempo para mim, porque trabalho de segunda a sábado. Gostaria de fazer visitas aos amigos e não consigo. (Vendedor, 41 anos, rede de eletrodomésticos e eletrônicos em Itaboraí).

Se eu pudesse, ficava cuidando dos meus filhos. Eles estão crescendo e eu não tô nem vendo. (Costureira, 41 anos, empresa de confecção).

A dura realidade evidenciada nas entrevistas dos comerciários, costureiras e operadores de telemarketing não é uma exclusividade destas categorias de trabalhadores. A tendência de enxugamento de direitos trabalhistas, precarização de condições de trabalho e outras consequências dos avanços da lógica do capital sobre o mundo do trabalho, estão presentes no cotidiano de quase todos os assalariados, inclusive dos assistentes sociais.

Os rebatimentos para o Serviço Social atingem uma dupla dimensionalidade: em primeiro lugar através do aumento da demanda de serviços colocada aos assistentes sociais por uma população usuária afetada por um amplo grau de precarização e exploração, como já assinalado. Em segundo lugar, o fato de os assistentes sociais também comporem o conjunto da classe trabalhadora, enquanto trabalhadores assalariados. Sendo assim, também sofrem os mesmos rebatimentos que atingem as outras categorias de trabalhadores (como redução dos postos de trabalho, redução salarial, péssimas condições de trabalho, vínculos precários, complexificação das atividades laborativas, etc.). Só para citar um exemplo:

Dados da Munic/IBGE (2006) revelavam que 25\% dos trabalhadores da área de assistência social nas administrações municipais de todo o país não possuíam vínculos permanentes, sendo $20 \%$ comissionados e apenas 38\% estatutários. Mais reveladores ainda foram os dados de 2007 extraídos da ficha de monitoramento dos CRAS (MDS, 2008, p. 30, Tabela 11), que revelavam que $48,8 \%$ dos trabalhadores dos CRAS não tinham vínculos permanentes, sendo 25,8\% estatutários, 13,5\% CLT e 12\% comissionados. (RAICHELIS, 2010, p. 762). 
Os dados e análises realizadas apontam para a necessidade de um longo percurso de organização e lutas pela superação da fragmentação e individualização decorrentes de uma lógica perversa capitalista que fragiliza todas as relações sociais.

\section{Considerações finais}

A pesquisa de campo articulada à discussão bibliográfica permitiu a comprovação dos impactos das transformações no mundo do trabalho no cotidiano dos trabalhadores entrevistados. Forneceu elementos para uma reflexão fundamental sobre a necessidade dos trabalhadores retomarem o controle sobre o tempo e todo o processo de trabalho, para que um dia possamos usufruir de uma vida dotada de sentido dentro e fora do trabalho, conforme expressão de Antunes (1999).

Em decorrência da realidade exposta pelos trabalhadores, como a precarização, a intensificação e flexibilização do trabalho, o tempo fora do trabalho, a saúde física e mental, as relações familiares, os estudos e o lazer vêm sendo cada vez mais afetados e dependentes das condições e relações vivenciadas no trabalho.

O excesso de horas extras, os trabalhos avulsos e totalmente irregulares (como o trabalho "autônomo" das costureiras) ao gerar uma perda do controle do tempo de trabalho, também impedem o planejamento da própria vida e prejudicam os relacionamentos sociais e afetivos dos trabaIhadores. Identificamos sempre um pesar em suas falas ao tratarem de planos para o futuro, do que gostariam de fazer e não conseguem devido a esse encurtamento do tempo livre fora do trabalho.

Ainda que a jornada de trabalho tenha sido reduzida em relação aos séculos anteriores, fica explícita a impossibilidade de realização de uma vida emancipada enquanto o trabalho - qualquer que seja sua duração - continuar voltado predominantemente à produção de valores de troca destinada apenas à valorização do capital, em total contradição com as necessidades da maioria da população. Logo, torna-se impossível a conciliação entre um sistema de trabalho subordinado e a emancipação humana.

Embora ainda parciais, os dados empíricos e o arcabouço teórico apresentado permitem concluir que o pleno desenvolvimento de todas as esferas do ser social somente poderá ser efetivado através do rompimento com a lógica do sistema produtor de mercadorias. Somente a produção de bens e serviços autodeterminada pelo conjunto da sociedade pode dar sentido à atividade laborativa e ao conjunto da vida social. Estamos falando aqui de uma nova sociabilidade, de indivíduos livremente associados. 


\section{ReVista all pavtg}

\} TRABALHO SUBORDINADO E QUALIDADE DE VIDA - GRAZIA, G. D.; SILVA, G. C.; MOREIRA, I. A. \}

\section{Referências}

ALVES, G. O novo (e precário) mundo do trabalho. São Paulo: Boitempo Editorial, 2000.

ANTUNES, R. Os sentidos do trabalho: ensaio sobre a afirmação e a negação do trabalho. São Paulo: Boitempo Editorial, 1999.

O caracol e sua concha: ensaios sobre a nova morfologia do trabalho. São Paulo: Boitempo Editorial, 2005.

Adeus ao trabalho? Ensaio sobre as metamorfoses e a centralidade no mundo do trabalho. 13 $3^{\mathrm{a}}$ ed. São Paulo: Cortez Editora, 2010.

BIHR, A. Da grande noite à alternativa. São Paulo: Boitempo Editorial, 1998.

BRASIL. MINISTÉRIO DO TRABALHO E EMPREGO (MTE). Anexo II DA NR-17. Portaria SIT n. 09, 30 de março de 2007. Diário Oficial da União, de 02 abr. 2007. <http://portal.mte.gov.br/data/files/FF8080812BE914E60 12BEFBDACD94B74/nr_17_anexo2.pdf>. Acesso em: 20 abr. 2012.

BULARD, M. Tempos modernos (versão hot line). Disponível em: <http:// www.diplomatique.org.br/acervo.php?id=253>. Acesso em 10 dez. 2003.

DE GRAZIA, G. Tempo de trabalho e desemprego: redução de jornada e precarização em questão. São Paulo: Xamã Editora, 2007.

DI RUZZA, R. Du temps de travail au temps du travail. In: GRUMBACH, T.; PINA, L. (Coord.) 35 heures: négocier les conditions du travail. Paris: Les Éditions de L'Atelier/ Éd. Ouvrières, 2000, p. 99-110.

GORZ, A. Adeus ao proletariado. Rio de Janeiro: Forense Universitária, 1982. HUSSON, M. Fin del trabajo o reducción de su duración? Veredas, México, n. 2, 2001.

MAGNIADAS, J. Réduction du temps de travail et nouvelle structuration des temps sociaux. Iseres. Paris, n. 17, 1996.

MARX, K. Trabalho assalariado e capital. São Paulo: Global Ed.1983, p.18. . O capital.v. I, Livro 1, Tomo I, 3a. ed. São Paulo: Ed. Nova Cultural, 1988.

OFFE, C. Trabalho: a categoria-chave da sociologia? Revista Bras. de Ciências Sociais, São Paulo, v. 4, n.10, p. 5-20, jun.1989.

OLIVEIRA, F. Crise financeira? Disponível em: <http://www.cartamaior. com.br/templates/materiaMostrar.cfm?materia_id=15900>. Acesso em: 02 abr. 2009.

PEPE, A. Il tempo, il tempo del lavoro e il tempo di lavoro industriale. Marxismo Oggi. Milano:Teti Editore, n. 2, p. 79-86, magg.-ag.1998. 


\section{heVista all pautg}

\} TRABALHO SUBORDINADO E QUALIDADE DE VIDA - GRAZIA, G. D.; SILVA, G. C.; MOREIRA, I. A. \}

RAICHELIS, R. Intervenção profissional do assistente social e as condições de trabalho no Suas. Serv. Soc. Soc., São Paulo, n. 104, p. 750-772, out./ dez. 2010.

RIFKIN, J. O fim dos empregos. São Paulo: Makron Books, 1995.

Recebido em 30 de setembro de 2012.

Aprovado para publicação em 14 de dezembro de 2012. 